\title{
Carvable silicone rubber prosthetic implant for atrophy of the first web in the hand
}

\author{
F DUERKSEN \& M VIRMOND \\ Health Sciences Centre, 700 William Avenue, GF 311 Winnipeg, \\ Manitoba, Canada R3E OZ3
}

Accepted for publication 19 January 1990

\begin{abstract}
Summary Muscular atrophy of the first web space in the hand is a common finding following ulnar nerve palsy and this deformity is very stigmatizing among leprosy patients in some countries and cultures.

We present our experience with the carvable soft-silicone rubber block implant to correct this deformity. We discuss the procedure, results and advantages over other techniques.

Fifteen operations were performed at the 'Lauro de Souza Lima' Research Institute, Bauru, Brazil during a period of six years. One complication was encountered due to an implant that was too large. The results were considered good in twelve instances and fair in three.
\end{abstract}

\section{Introduction}

Muscular atrophy of the first web space in leprosy is common following ulnar nerve palsy. The shallow aspect of this space is due to atrophy of the first dorsal interosseous and the adductor pollicis muscles (Figure 1).

From the social point of view and with some cultural differences, this deformity is one of the most stigmatizing signs among leprosy patients. In Brazil, we have seen that this deformity is considered by the public and the patients as one of the most stigmatizing deformities together with madarosis and megalobule.

Different surgical techniques have been described in order to restore fullness of the first web space and solve this aesthetic problem. We intend to discuss some of these surgical techniques and present our experience with a carvable silicone implant.

\section{Materials and method}

We operated on thirteen patients with leprosy and one with longstanding ulnar nerve damage secondary to trauma. The ages ranged from 21 to 67 years. Eleven patients were male and three female. Six were classified as lepromatous, seven as borderline and one as 


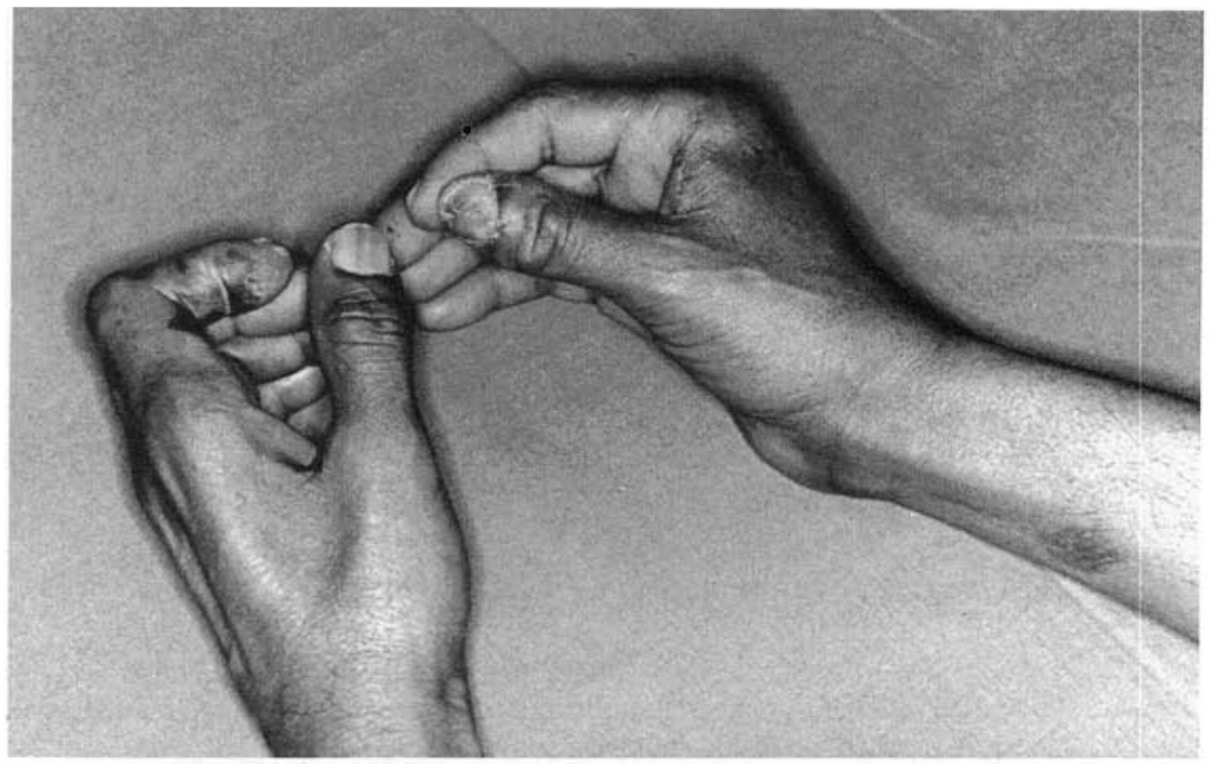

Figure 1. Marked atrophy of the first web space in the left hand. The right hand has been operated on with silicone implant.

tuberculoid. All leprosy patients were under regular treatment of dapsone or MDT for at least one year prior to the operation and any tendon transfer either for claw hand or lack of opposition were performed prior to the silicone implant. The total number of hands operated on was 15 .

\section{SURGICAL PROCEDURE}

Local anesthesia was used in all cases. A 2-cm incision was made along the first web following the interdigital line and close to the index finger. A pocket was created through this incision by blunt dissection between the paralysed fibres of the adductor pollicis and the first dorsal interosseous preserving both fasciae. Having estimated the pocket size, a silicone piece was cut from a soft silicone block (Silastic Dow Corning) and was carefully carved with fine and sharp scissors. We used two basic designs-fusiform and elliptical (Figure 2). After thoroughly rinsing the carved piece and the pocket with saline solution, the prothesis was introduced (Figure 3). Two or three fine nylon sutures were used to close the deep fascia, closing securely the pocket. The skin was then closed with interrupted $6 / 0$ nylon stitches. A plaster cast was applied and two weeks later all dressings and sutures were removed.

\section{Results}

We used two parameters to evaluate the results: preoperative and postoperative abduction angle and preoperative and postoperative cosmetic appearance. A goniometer 


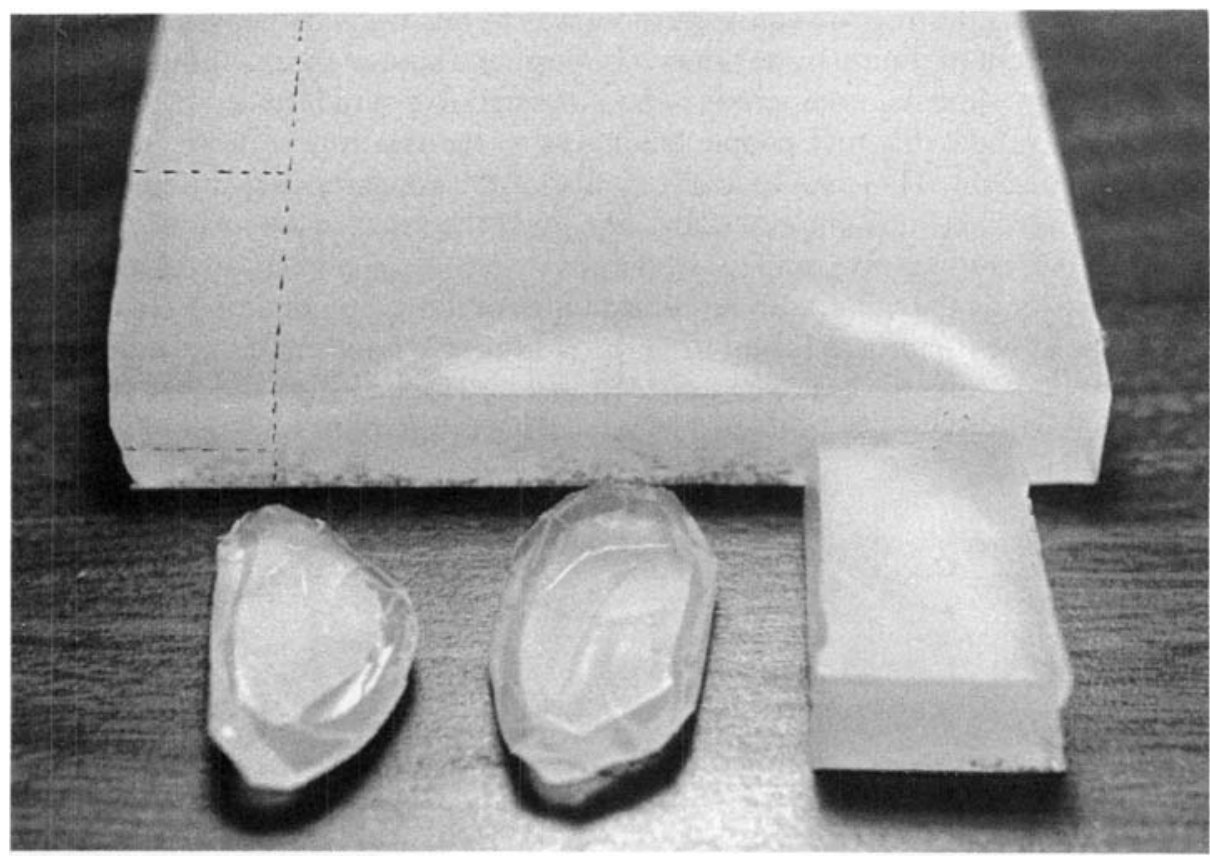

Figure 2. Soft silicone-rubber block, the dotted lines indicate primary cuts. For small hands each piece can be divided into two halves. Two basic designs are used: fusiform and elliptical, seen on the left-hand side).

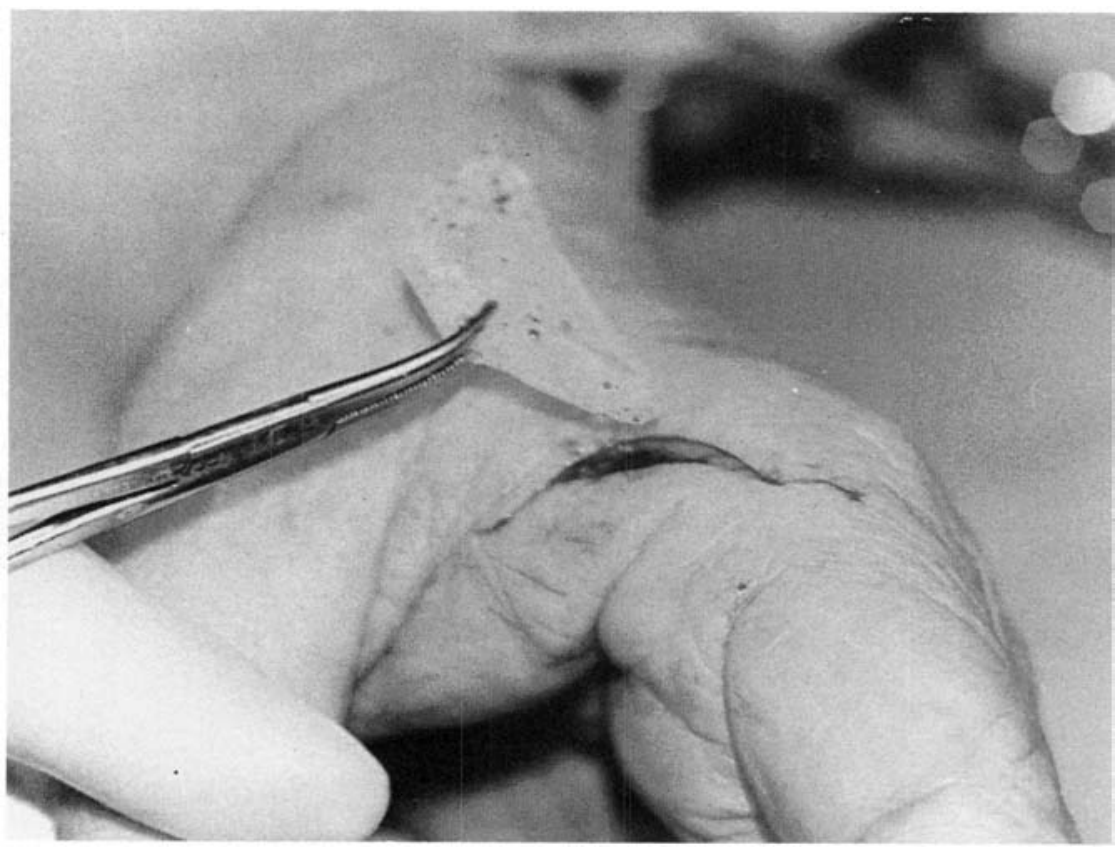

Figure 3. The carved implant ready for insertion. 
was used to obtain the angles and the purpose was to find out whether the implant could create any problem to thumb opposition. The cosmetic appearance, although subjective, was evaluated by showing preoperative and postoperative standardized black and white photographs to three different people belonging to the Institute staff but not from the Surgical Department. They had to answer whether the appearance had improved (good result), not improved substantially (fair), remained the same or was worse (poor). The analysis of the preoperative and postoperative abduction angles revealed that they remained essentially the same, with no contractures or limitation of motion to the thumb. The cosmetic appearance was found to be good in twelve hands and fair in three by the independent observers. No case was recorded as poor (Figures 4(a) and (b)). All patients were satisfied with the result in their own subjective evaluation.
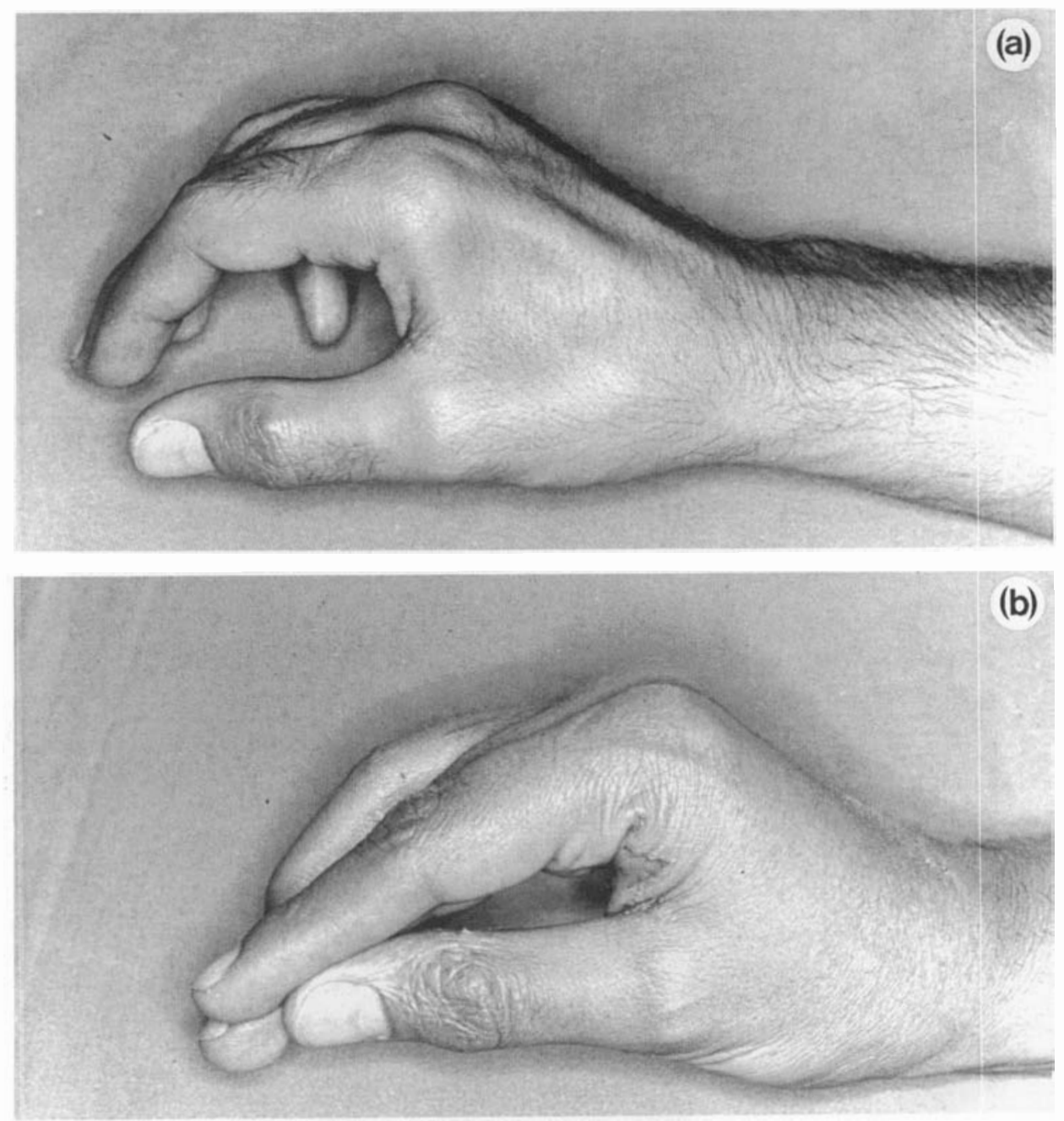

Figure 4. Preoperative and postoperative views. 


\section{Discussion}

The most evident wasting or atrophy in the hand is the atrophy of the first web secondary to ulnar nerve palsy and in endemic countries there is a close association of this deformity with leprosy.

A variety of techniques have been described to correct this atrophy both with autogenous and alloplastic materials. In the autogenous tissue group, fat grafts have been used but they are likely to loose up to one half of their original bulk. Dermal or dermal-fat grafts are probably the most useful autogenous grafts ${ }^{1,3}$ although they present similar problems. Fascia lata grafts have been used $^{3}$ but these also scar down, retract and lose their bulk.

Concerning alloplastic materials the most suitable is medical silicone. The use of silicone gel injection is definitely not recommended due to many serious complications that have been described. ${ }^{5,6}$ The use of silicone gel contained in a bag, like the testicular implant, ${ }^{4}$ would seem to be the most feasible because it mimics exactly the tissue consistency of the first web, although the three sizes available for these implants are too large for most hands and also the cost of each one is very high. We have used custom made gel bag implants but the cost is also too high for leprosy patients, usually living in developing countries.

The soft carvable silicone block (Silastic Dow Corning) has a consistency slightly

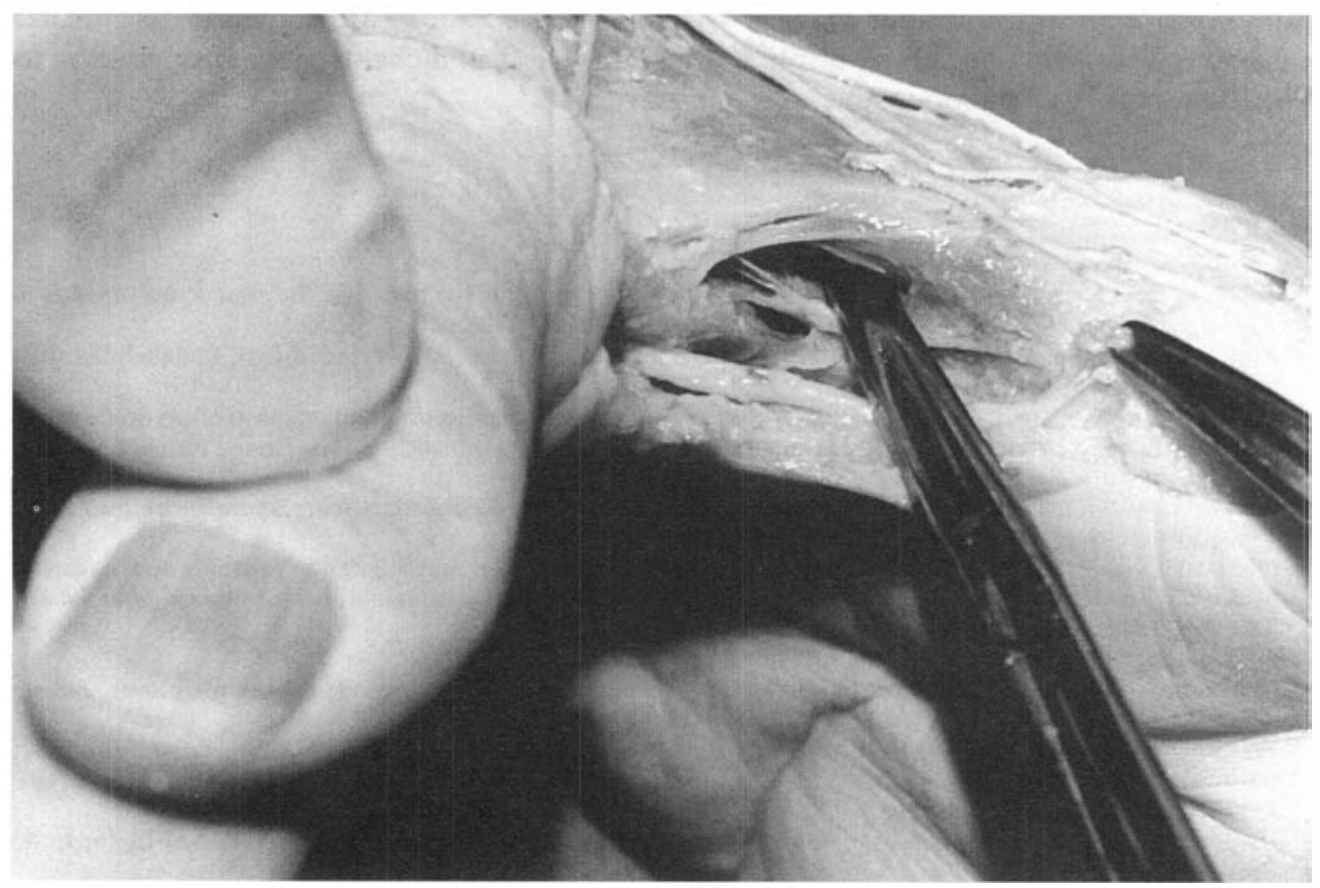

Figure 5. Anatomical dissection demonstrating the pocket between first dorsal interosseous and adductor pollicis. 
harder than the normal muscle tissues in the first web but it is easy to carve and economic since we can produce an implant with a cost of less than US\$ 10.00 each.

Most complications related to medical silicone are related to the use of injectable gel ${ }^{5,6}$ or to silicone implants in joints where they are subjected to extreme wear and tear, causing particles to be freed which can get into limphatic or venous circulation. ${ }^{7-9}$ The incidence of complications is really very small considering the thousands of implants that have been used over the years. However, we plan to keep a close follow-up study of our patients over the next years.

The use of silicone rubber carved implants in leprosy patients was described in 1967 by Reginato ${ }^{10}$ but we believe that the newer soft silicone blocks give a more natural feel and that the exact place of implantation must be the space between the first dorsal interosseous and the adductor pollicis. This gives a good tissue cushion on both sides to protect the implant from trauma and avoid extrusion (Figure 5).

\section{COMPLICATIONS}

In our series we had one complication. A patient had a partial extrusion from the pocket because the implant was too large. This was solved by reshaping it to a smaller size and adequate closure of the pocket. The final result was good.

\section{Conclusions}

Analysing the results obtained and the aspects discussed above, we conclude that the use of a carved soft silicone rubber implant is a simple, safe and cheap procedure, leading to very satisfactory cosmetic results.

\section{References}

1 Johnson HA. Dermal grafts for post-leprosy muscular wasting in the hand. In Surgical Rehabilitation in Leprosy. McDowell F, Enna GD (eds) Baltimore: Williams \& Wilkins, p 273, 1974.

${ }^{2}$ Peer LA. Transplantation of fat in Reconstructive and Plastic Surgery. Converse JM (ed), Philadelphia: WB Saunders \& Company, p 109, 1969.

3 Reginato LE, Homem de Mello P, Belda W. Ensaio da Correcao das deformidades amiotroficas do dorso da mao por un novo metodo: Enxertos Dermicos e Retalhos Dermogordurosos e Enxertos de Fascia Lata. Rev Lat Amer Cirurg Plast, 1966; 10: 78.

4 Zacharia AG, Gelber RN. Silastic implant of thefirst dorsal interosseous space (correspondence). Int J Lepr, 1985; 53(4): 643.

5 Okano Y, Nishikai M, Sato A. Scleroderma, primary biliary cirrhosis and Sjogren's syndrome after cosmetic breast augmentation with silicone injection: a case report of possible human adjuvant disease. Ann Rheum Diseases, 1984; 43: 520.

${ }^{6}$ Silicone pneumonitis (editorial). Lancet Oct. 1983: 833.

7 Gordon M, Bullough PG. Synovial and osseous inflammation in failed silicone-rubber prosthesis. $J$ Bone Joint Surg, 1982; 64-A, No. 4: 574.

${ }^{8}$ Worsing RA, Engber WD, Lange TA. Reactive synovitis from particulate silastic. J Bone Joint Surg, 1982; 64-A, No. 4: 581.

9 Smith RJ, Atkinson MD, Jupiter JB. Silicone synovitis of the wrist. J Hand Surg, 1985; 10A: 47.

10 Reginato LE, Belda W. Correcao das Deformidades Amiotroficas do Dorso da Mao pelo Uso de Inclusoes de Silicone Liquido e Solido. Rev Brasil de Leprologia, 1967; 35: Dec. 